\title{
Upaya Fakultas Kedokteran, Kesehatan Masyarakat, dan Keperawatan Universitas Gadjah Mada dalam penanggulangan banjir di Kota Bima dengan teknologi pemanen air hujan
}

\author{
Sutono, ${ }^{1}$ Bayu Fandhi Achmad, ${ }^{1, *}$ Citra Indriani, ${ }^{2}$ Dyah Ayu Wulansari, ${ }^{3}$ Agus Salim Arsyad, ${ }^{4}$ Hari \\ Kusnanto, ${ }^{5}$ Agus Maryono, ${ }^{6}$ Rifqi Amrillah Abdi ${ }^{6}$
}

\begin{abstract}
${ }^{1}$ Departemen Keperawatan Dasar dan Emergensi, ${ }^{2}$ Departemen Biostatistik, Epidemiologi, dan Kesehatan Populasi, ${ }^{3}$ Residen Program Studi S2 IImu Kedokteran Klinik, ${ }^{4}$ Mahasiswa S2 Program Studi Ilmu Kesehatan Masyarakat, ${ }^{5}$ Departemen Kedokteran Keluarga, Komunitasi, dan Bioetika, Fakultas Kedokteran, Kesehatan Masyarakat, dan Keperawatan, Universitas Gadjah Mada, Yogyakarta, Indonesia ${ }^{6}$ Program Studi Teknik Sipil, ${ }^{7}$ Mahasiswa D3 Program Studi Teknik Sipil, Sekolah Vokasi, Universitas Gadjah Mada, Yogyakarta, Indonesia
\end{abstract}

\section{Submitted: 21 Juli 2018 Revised: 7 November 2018 Accepted: 16 November 2018}

\begin{abstract}
ABSTRAK Bencana banjir yang terjadi di Kota Bima, Nusa Tenggara Barat di akhir tahun 2016 menyebabkan 105.753 jiwa terdampak langsung oleh banjir yang terjadi di hampir seluruh kota. Universitas Gadjah Mada (UGM) melalui Fakultas Kedokteran, Kesehatan Masyarakat, dan Keperawatan (FK-KMK) yang didukung oleh Keluarga Alumni Universitas Gajah Mada Fakultas Kedokteran (KAGAMADOK) mengirimkan dua tim secara bertahap ke Kota Bima untuk melakukan pengkajian gangguan kesehatan akibat banjir di lokasi pengungsian dan pembuatan alat pemanen air hujan (PAH). Tim pertama bertugas untuk melakukan pencatatan terhadap gangguan kesehatan dan kebutuhan pengungsi serta merujuk pengungsi bila ditemukan kasus penyakit. Tim kedua bertugas untuk menerapkan teknologi alat PAH sesuai dengan hasil pengkajian yang telah dilakukan oleh tim pertama. Hasil pengkajian tim pertama menunjukkan bahwa angka kejadian penyakit kulit tinggi, namun stok obat penyakit kulit menipis, meningkatnya kasus diare khususnya pada anak-anak, dan terbatasnya database kesehatan di Kota Bima. Oleh karena itu, tim pertama melakukan pendataan kesehatan pada warga dan memberikan pelayanan kesehatan di rumah sakit lapangan milik Tentara Nasional Indonesia (TNI). Tim kedua mengaplikasikan teknologi PAH berdasarkan hasil kajian tim pertama yang menunjukkan bahwa air tanah di daerah bekas banjir masih keruh dan berbau kurang sedap. Alat PAH diaplikasikan di Puskesmas Penanae dan Puskesmas Mpunda. Diterjunkannya Tim UGM ke Bima diharapkan dapat memberikan manfaat kepada warga terdampak banjir. Selain itu, diharapkan pendampingan dari UGM dapat terlaksana secara berkelanjutan.
\end{abstract}

KATA KUNCI Bima; penanggulangan bencana; banjir; alat pemanen air hujan

ABSTRACT Flood disaster in Bima Town, West Nusa Tenggara Province, Indonesia at the end of 2016 affected 105,753 people. Universitas Gadjah Mada (UGM) represented by Faculty of Medicine, Public Health, and Nursing supported by the Faculty of Medicine Alumni Association (KAGAMADOK) sent two response teams to the disaster area with the aims to assess health status of the refugees and to create rainwater harvesting tool. First team assigned to establish database and health cluster information analysis, performed needs assessment at refugee camp and affected area, and sent the patient to emergency health service. Regarding to the first team assessment results, second team assigned to create rainwater harvesting tool. First UGM team discovered that communities experiencing high prevalence of dermatology disease, meanwhile the

\footnotetext{
*Corresponding author: Bayu Fandhi Achmad

Departemen Keperawatan Dasar dan Emergensi, Fakultas Kedokteran, Kesehatan Masyarakat, dan Keperawatan, Universitas Gadjah Mada, Jl. Farmako, Sekip Utara, Yogyakarta 55281, Indonesia

E-mail: bayu.fandhi.a@ugm.ac.id
} 
medicine livestock diminished. Escalation of diarrhea cases especially in children and limited community health surveillance in Bima Town were also identified by the team. The second team was in a mission to accomplish environmental studies associated with flood disaster and implement rainwater harvesting technology. Rainwater harvesting technology implemented based on data collection and analysis from the first team. Rainwater harvesting technology used to supply community water necessities since the groundwater in disaster area remain muddy and smells. Application of rainwater harvesting equipment completed at Penanae and Mpunda Primary Health Care. Deployment of the UGM Bima disaster response team expected to spring positive benefits to the flood affected communities, and in addition expected that the assistance from UGM established sustainably.

KEYWORDS Bima; disaster management; flood; rainwater harvesting tool

\section{Pendahuluan}

Bencana banjir yang terjadi di Kota Bima, Nusa Tenggara Barat, terjadi pada tanggal 21 Desember 2016 dan diikuti banjir susulan pada tanggal 23 Desember 2016. Berdasarkan data dari Badan Penanggulangan Bencana Daerah (BPBD) Kota Bima, sebanyak 105.753 jiwa (66\% penduduk Kota Bima) terdampak langsung oleh banjir yang terjadi di hampir seluruh kecamatan di Kota Bima. Banjir tersebut merendam rumah penduduk dengan ketinggian 1 - $3 \mathrm{~m}$ sehingga mengakibatkan 593 rumah rusak berat, 2.400 rumah rusak sedang, dan 16.226 rumah rusak ringan. ${ }^{1}$

Secara geografis, Kota Bima terletak di bagian timur Pulau Sumbawa pada posisi $118^{\circ} 41^{\prime} 00^{\prime \prime}$ $118^{\circ} 48^{\prime} 00^{\prime \prime}$ Bujur Timur dan $8^{\circ} 20^{\prime} 00^{\prime \prime}-8^{\circ} 30^{\prime} 00^{\prime \prime}$ Lintang Selatan. Kota Bima memiliki luas wilayah $222,25 \mathrm{~km}^{2}$ yang terbagi menjadi 5 kecamatan, yaitu Raba, Mpunda, Rasanae Barat, Rasanae Timur, dan Asakota. ${ }^{2}$ Berdasarkan Indeks Risiko Bencana Indonesia (IRBI) dari Badan Nasional Penanggulangan Bencana (BNPB) (2013), Kota Bima berada pada kelas risiko tinggi dengan skor 171 dengan ancaman risiko bencana meliputi banjir, gempa bumi, tanah longsor, kekeringan, cuaca ekstrem, dan tsunami. Bencana banjir di Kota Bima merupakan risiko bencana yang tergolong dalam kelas risiko tinggi dengan skor 36. Hal tersebut disebabkan karena Kota Bima memiliki kontur wilayah yang beragam, mulai dari kontur perbukitan di bagian pinggir sampai dataran rendah di pusat kota, sehingga terlihat seperti mangkuk dengan pusat Kota Bima berada di dasar mangkuk. Hal tersebut menyebabkan aliran sungai terlebih dahulu menuju ke wilayah pusat kota sebelum berakhir di laut. ${ }^{3}$

Masalah yang dihadapi oleh warga Kota Bima yaitu manajemen sampah pasca banjir yang masih belum tertangani dengan baik. Sampah domestik masih menggunung di pinggir jalan dan belum sepenuhnya terangkut. Sampah dan air kotor pasca banjir yang tidak tertangani tersebut berpotensi besar mencemari air tanah. Hal tersebut terbukti dari kondisi air tanah yang berasa dan berbau tidak sedap sehingga menimbulkan kekhawatiran masyarakat. Selain itu, kondisi sungai terlihat telah terokupasi oleh pemukiman masyarakat bantaran sungai. Pada bibir sungai sudah dibangun tembok batu sehingga ekosistem sekitar sungai mati. ${ }^{1}$

Merespon kejadian bencana banjir di kota Bima, Universitas Gadjah Mada melalui Fakultas Kedokteran, Kesehatan Masyarakat, dan Keperawatan (FK-KMK) yang didukung oleh Keluarga Alumni Universitas Gajah Mada Fakultas Kedokteran (KAGAMADOK), mengirimkan dua tim ke wilayah bencana Kota Bima yang diberangkatkan dalam dua tahap. Tujuan dari pengiriman tim tersebut adalah untuk melakukan pengkajian gangguan kesehatan akibat banjir di lokasi pengungsian dan pembuatan alat pemanen air hujan (PAH). 


\section{Metode}

Tim penanggulangan banjir dibagi dua. Tim pertama terdiri dari dokter, perawat, dan ahli kesehatan masyarakat. Tim tersebut diterjunkan pada tanggal 30 Desember - 3 Januari 2017. Selama pelaksanaan kegiatan tim melakukan observasi lapangan. Kegiatan diawali dengan melakukan pengamatan dan pencatatan penyakit atau gangguan kesehatan pada lokasi pengungsian di Kecamatan Raba, Mpunda, Rasanae Barat, Rasanae Timur, dan Asakota. Apabila berdasarkan hasil pengamatan yang dilakukan ditemukan kasus maka pasien akan dirujuk ke pos komando (posko) kesehatan di Kantor Walikota Bima untuk mendapatkan pengobatan gratis.

Tim kedua merupakan tim kolaboratif antara bidan dan ahli hidrologi. Tim kedua diterjunkan pada tanggal 18 - 21 Januari 2017 dan melaksanakan kegiatan dengan menerapkan teknologi alat pemanen air hujan (PAH) di dua pusat kesehatan masyarakat (puskesmas), yaitu Puskesmas Mpunda dan Puskesmas Penanae. Mpunda dan Penanae dipilih karena kedua tempat tersebut memiliki air tanah yang berwarna dan berbau kurang sedap akibat banjir sehingga air tanah di kedua tempat tersebut tidak direkomendasikan untuk dikonsumsi.

Air hujan yang didapatkan dari alat PAH diuji secara fisik dan biologis di Balai Laboratorium Kesehatan Yogyakarta. Saat pengambilan sampel air dari alat PAH, keran dibakar agar steril, air pertama dibuang, lalu air kedua diambil sebagai sampel. Pengambilan sampel dilakukan sebanyak dua kali. Standar yang digunakan sebagai pembanding adalah standar baku mutu air bersih berdasarkan Permenkes No. 416/Menkes/Per/IX/1990.

\section{Hasil}

\subsection{Tim Bima Pertama}

Tim UGM tiba di Bandara Sultan M. Salahudin Bima pada tanggal 30 Desember 2016 pukul 14.00 WITA dan melapor ke ruang posko klaster kesehatan di Kantor Walikota Bima yang dipakai sebagai posko penanganan banjir Kota Bima. Permasalahan yang ditemukan di posko klaster kesehatan adalah terbatasnya sumber daya manusia yang melakukan pencatatan sehingga tim membantu pencatatan data penyakit akibat bencana banjir di Kota Bima.

Penyakit yang ditemukan pasca banjir salah satunya yaitu campak (Gambar 1). Salah satu faktor penyebab terjadinya kejadian luar biasa (KLB) campak pada anak-anak di kelurahan Paruga dan Penanae adalah masih kurangnya kesadaran pemberian vaksin pada anak-anak. Rusaknya tempat penyimpanan vaksin dan gudang obat serta alat-alat kesehatan di empat puskesmas, yaitu Puskesmas Penanae, Puskesmas Paruga, Puskesmas Mpunda, dan Puskesmas Ranggo mengakibatkan terputusnya pemberian vaksin dan pengobatan rutin untuk penyakit-penyakit infeksi kronis.

Selain itu, pencatatan dan pelaporan pada saat bencana masih lambat. Hal tersebut disebabkan oleh belum adanya sistem yang dirancang untuk siap menghadapi bencana sehingga sistem pencatatan pelaporan yang seharusnya terus berjalan untuk memantau status kesehatan masyarakat terhambat. Kasus penyakit menular seperti campak, leptospirosis, dan penyakit kulit diprediksi akan terus meningkat akibat kondisi lingkungan yang memburuk. Infeksi saluran pernapasan atas (ISPA) juga akan meningkat akibat buruknya kualitas udara di wilayah bencana.

Penyakit yang ditemukan kemudian dirujuk ke rumah sakit lapangan milik Tentara Nasional Indonesia (TNI). Jumlah pasien per hari kurang lebih 200 pasien yang terdiri dari anak, orang dewasa, ibu hamil, dan orang lanjut usia dengan keluhan terbanyak adalah penyakit kulit, ISPA, dan nyeri kepala. Pada hari ketiga, tim UGM membantu memberikan pelayanan medis di rumah sakit lapangan TNI dan melakukan pendataan dengan fokus anak di bawah lima tahun (balita) yang diduga menderita campak (Gambar 2). Campak menjadi fokus perhatian Dinas Kesehatan Kota Bima karena ditemukan kasus di lokasi pengungsian Kelurahan Penaraga. Saat itu juga sudah dimulai vaksinasi campak dengan sasaran balita yang tinggal di lokasi pengungsian. Pendataan dilakukan di 14 lokasi pengungsian. Pada beberapa wilayah pengungsian ditemukan kasus diare dan bayi dengan riwayat 


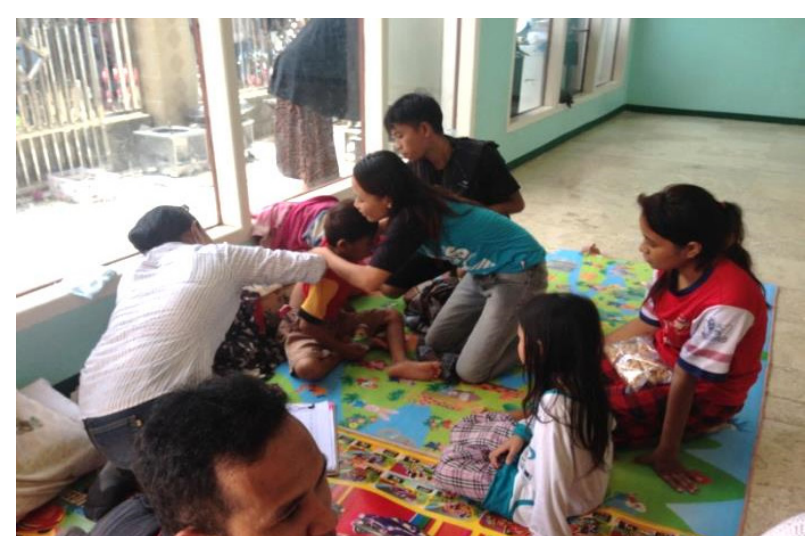

(a)

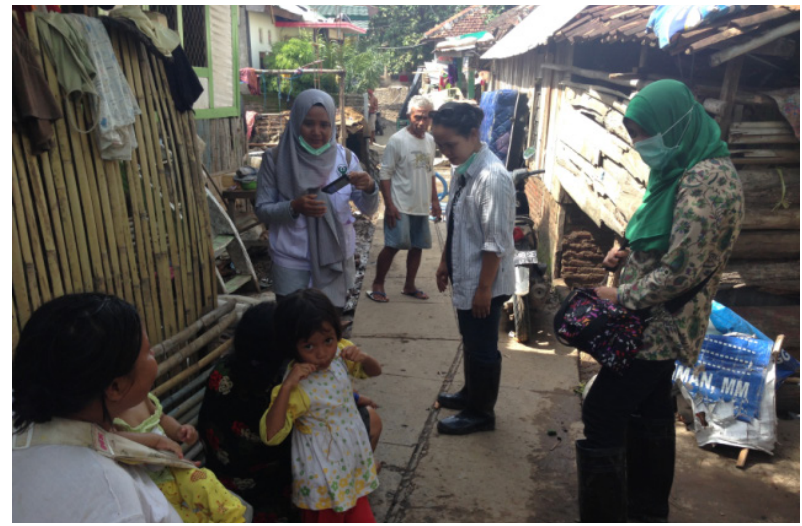

(b)

Gambar 1. Proses observasi lapangan untuk mengamati kondisi lingkungan sekaligus menemukan penyakit. (a) Temuan penderita campak oleh tim medis UGM. (b) Pengamatan pola higiene pada anak-anak dan sanitasi

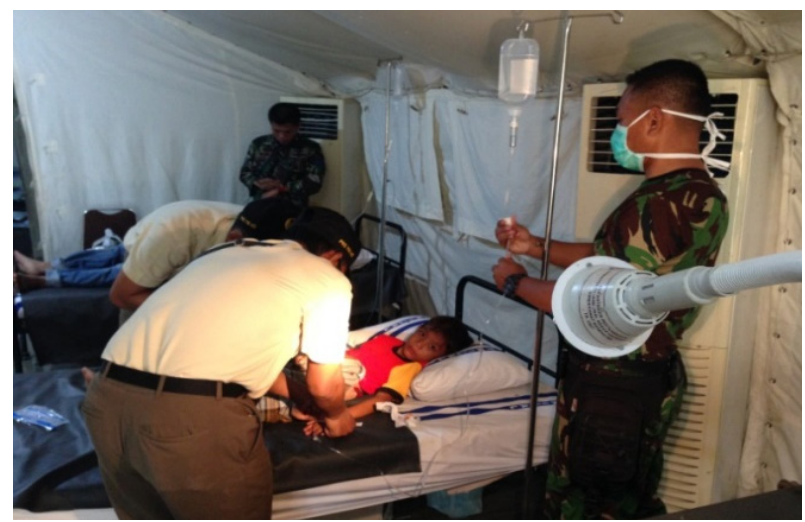

(a)

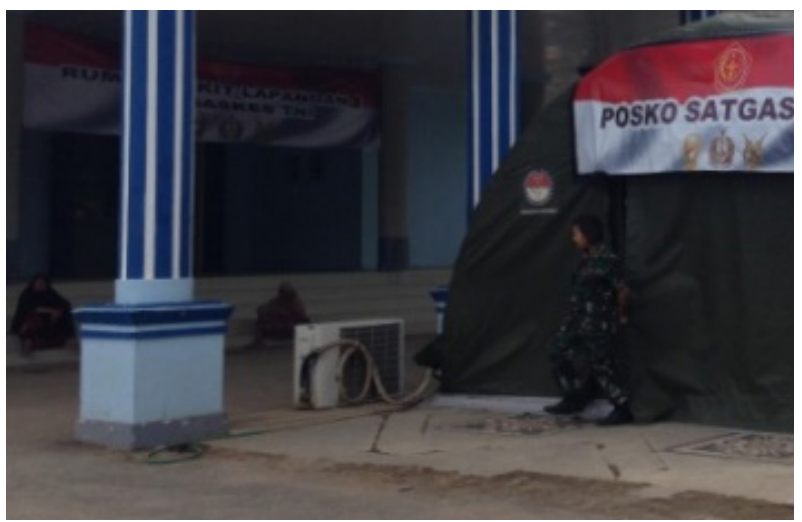

(b)

Gambar 2. Pelayanan kesehatan yang dilaksanakan oleh tim UGM di RS Lapangan TNI

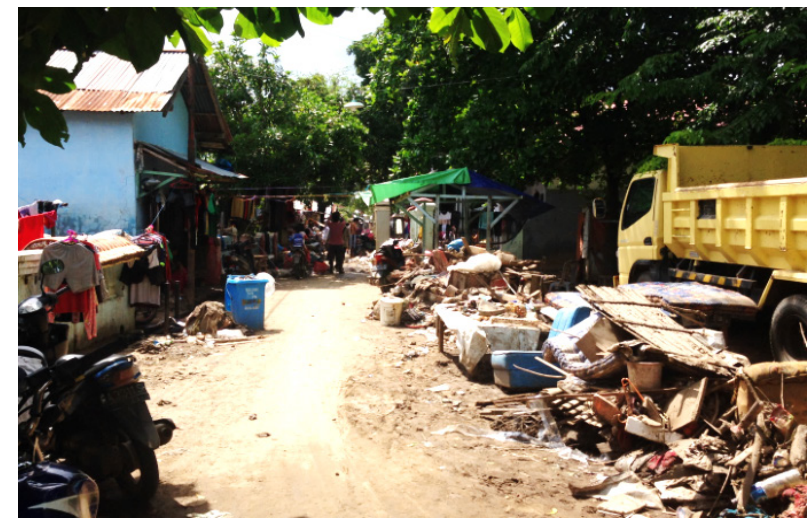

(a)

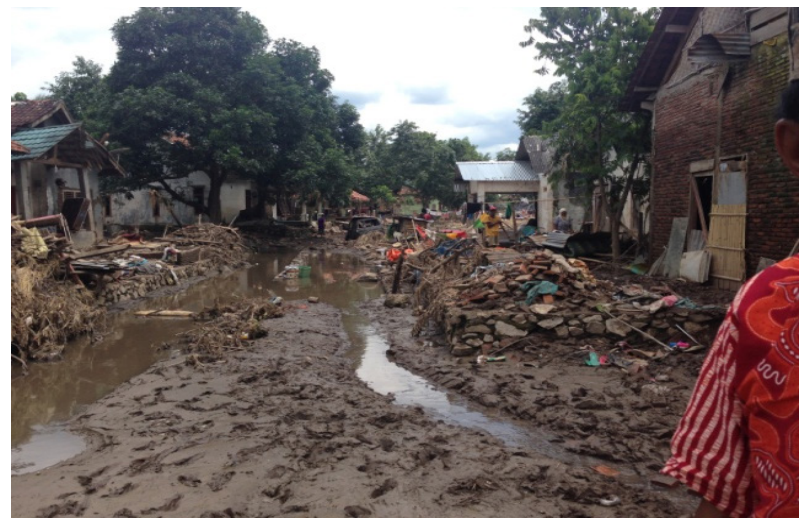

(b)

Gambar 3. Penumpukan lumpur dan sampah di jalan kampung dan jalan besar

berat badan lahir rendah (BBLR) yang tidak mendapatkan air susu ibu (ASI) ekslusif. Pengadaan makanan pendamping ASI dan makanan suplemen untuk ibu hamil serta bantuan logistik juga masih belum merata. Pola higiene dan sanitasi di lingkungan pengungsi kurang baik sehingga berpotensi menimbulkan penyakit kulit dan ISPA.

Penumpukan lumpur bercampur sampah serta material bangunan menambah buruknya sanitasi lingkungan. Manajemen evakuasi lumpur 
dan sampah oleh dinas terkait masih sangat kurang sehingga menimbulkan tumpukan lumpur dan sampah mulai dari dalam rumah, sepanjang gang masuk kampung, hingga pinggir jalan besar (Gambar 3). Bau busuk dari sampah merata di sebagian lokasi banjir Kota Bima. Tokoh masyarakat korban banjir mengatakan bahwa pembuangan lumpur dan sampah menjadi permasalahan besar karena Kota Bima tidak mempunyai pembuangan sampah akhir. Mereka juga mengeluhkan bahwa fasilitas yang dimiliki oleh dinas terkait seperti truk sampah dan tempat pembuangan sampah sementara terbatas.

\subsection{Tim Bima kedua}

Tim kedua yang diterjunkan ke Bima pada tanggal 18 - 21 Januari 2017 terdiri dari 4 orang yang

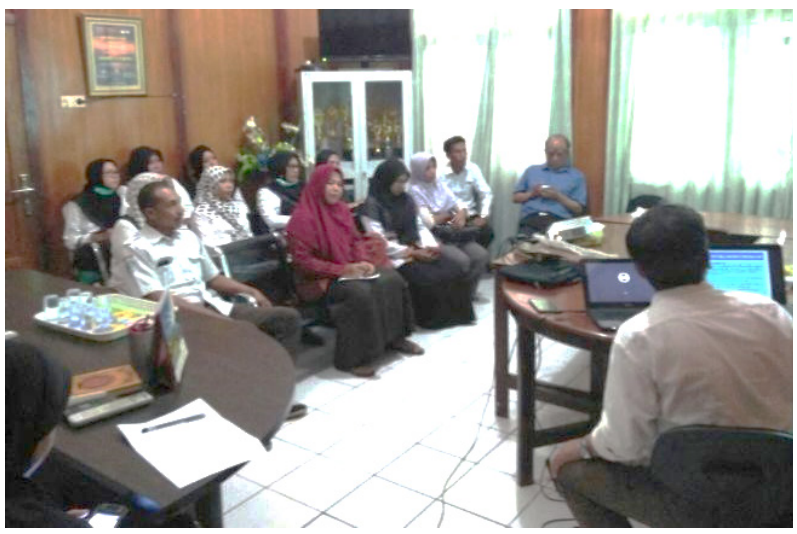

(a) memfokuskan diri pada penerapan teknologi alat PAH. Dasar dari perlunya penerapan alat PAH tersebut adalah kondisi air tanah yang masih berwarna dan berbau kurang sedap sehingga masih belum layak untuk dikonsumsi.

Tim selanjutnya dibagi menjadi dua yaitu satu grup bergerak ke Kantor Dinas Kesehatan Kota Bima untuk mempresentasikan teknologi alat PAH kepada perwakilan Puskesmas dan Dinas Kesehatan Kota Bima (Gambar 4), serta satu grup yang lain bergerak mempersiapkan berbagai alat dan bahan yang akan digunakan untuk pembuatan alat PAH tersebut. Dalam presentasi tersebut tim menyampaikan materi filosofi memanen air hujan, manfaat memanen air hujan, keunggulan air hujan dibandingkan dengan air dari Perusahaan Daerah Air Minum (PDAM) dan sumur bor, masalah-

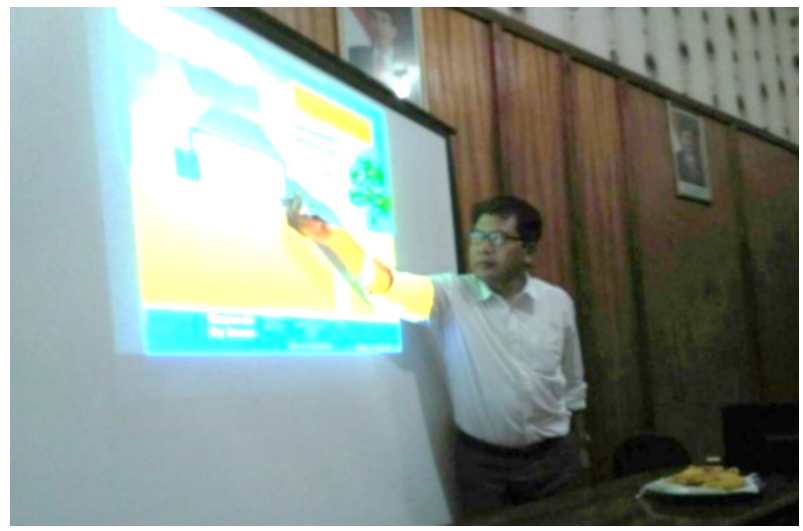

(b)

Gambar 4. Presentasi dan diskusi mengenai teknologi alat PAH dengan pihak Puskesmas dan Dinas Kesehatan Kota Bima

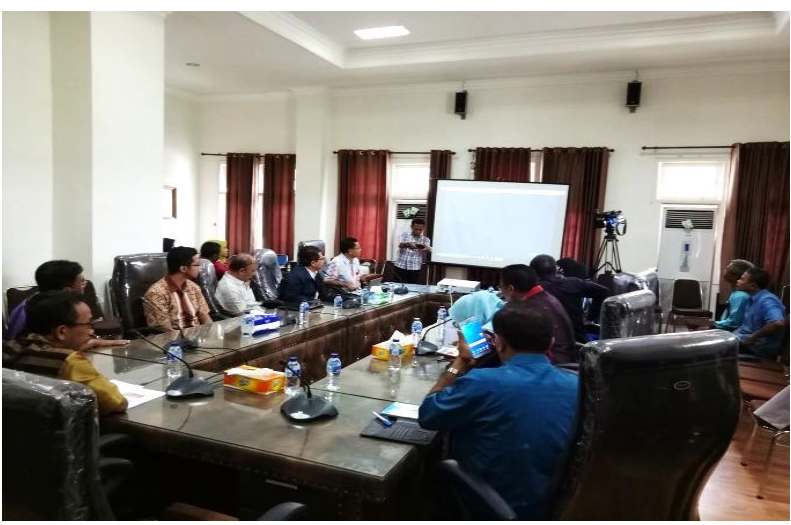

(a)

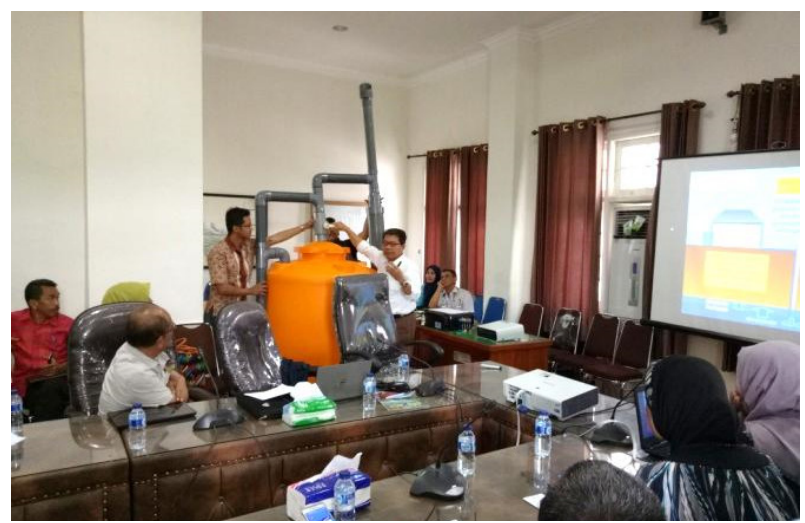

(b)

Gambar 5. Presentasi dan demonstrasi alat PAH di Kantor Walikota Bima. (a) Presentasi di hadapan berbagai pihak terkait. (b) Demonstrasi cara penggunaan dan pemanfaatan alat PAH 
Tabel 1. Hasil uji air yang dipanen dari alat PAH

\begin{tabular}{lc}
\hline Parameter & Hasil uji \\
\hline Bau & Tidak berbau \\
Rasa & Tidak berasa \\
Warna, skala TCU & 10,000 \\
Kekeruhan, skala TCU & 0,400 \\
Zat padat terlarut (TDS), & \\
$\mathrm{mg} / \mathrm{L}$ & 3,000 \\
$\mathrm{pH}$ & 6,120 \\
Klorida (Cl-), mg/L & $<2,85$ \\
Kesadahan (CaCo3), mg/L & 4,000 \\
Zat organik (KMnO4), mg/L & 1,000 \\
Sulfat (SO4-), mg/L & $<1,000$ \\
Fluorida (F-), mg/L & 0,067 \\
Nitrit (NO2- - N), mg/L & 0,002 \\
Nitrat (NO3- - N), mg/L & 0,528 \\
Besi (Fe), mg/L & 0,138 \\
Mangan (Mn), mg/L & 0,182 \\
Sianida (CN), mg/L & $<0,006$ \\
Gol. Coliform, MPN/100 ml & $<1,800-2,000$ \\
\hline TCU: true color unit; TDS: total dissolved solid; MPN: \\
most problaby number
\end{tabular}

masalah yang timbul terkait dengan air tanah, dan cara membuat alat PAH.

Pada hari kedua tim mengadakan presentasi dan demonstrasi alat PAH di ruang rapat Kantor Walikota Bima yang dihadiri oleh perwakilan dari Dinas Kelautan, Dinas Pemukiman, Badan Ketahanan Pangan dan Penyuluhan (BKP2), Dinas Pertanian, Dinas Pariwisata, Badan Kepegawaian Daerah (BKD), Dinas Koperasi, Perindustrian dan Perdagangan, Kepala Bagian Kesejahteraan Rakyat, Dinas Kesehatan, Badan Kesatuan Bangsa dan Politik, Kepala Bagian Administrasi Pemerintahan, Dinas Pekerjaan Umum, dan Badan Perencanaan Pembangunan Daerah (Gambar 5). Kegiatan tersebut diawali dengan presentasi mengenai restorasi sungai dan pemanfaatan air hujan. Kemudian dilanjutkan dengan demonstrasi mengenai pemanfaatan PAH. Kegiatan tersebut ditutup dengan sesi tanya jawab di mana banyak pertanyaan yang diberikan. Hal tersebut menunjukkan bahwa peserta kegiatan memiliki respon yang sangat positif terhadap alat PAH.
Hari ketiga diawali dengan rapat di Kantor Dinas Kesehatan Kota Bima yang dipimpin oleh Sekretaris Kepala Dinas Kesehatan Kota Bima untuk menentukan lokasi pemasangan alat PAH. Dari hasil rapat ditetapkan bahwa PAH akan dipasang di Puskesmas Penanae dan Mpunda karena wilayah kerja kedua puskesmas tersebut memiliki kualitas air tanah yang paling buruk. Setelah rapat tim segera bergerak menuju lokasi pertama yaitu Puskesmas Penanae untuk melakukan pemasangan. Setelah mendapat izin dari Kepala Puskesmas Penanae, tim melakukan pemasangan alat tersebut. Kendala yang dihadapi adalah hujan yang turun cukup lama sehingga menghambat proses pemasangan alat, namun setelah hujan berhenti, tim dapat kembali bekerja seperti biasa. Selanjutnya tim bergerak ke Puskesmas Mpunda untuk memasang alat PAH yang kedua.

Setelah alat PAH dipasang, tim mengambil sampel air dari alat PAH untuk diuji secara fisik dan biologi guna mengetahui kualitas air yang dihasilkan dari alat PAH. Air hujan yang dipanen dengan alat PAH mengandung Coliform di bawah ambang batas standar baku mutu air bersih (Tabel 1). Dilihat dari segi fisik, air hasil PAH tidak menunjukkan adanya penyimpangan.

\section{Pembahasan}

Pada upaya penanggulangan banjir Kota Bima, tim pertama menemukan bahwasampah pasca bencana masih berada di lingkungan pemukiman dan fasilitas umum. Selain itu, belum ada manajemen sampah yang sistematis dan terintegrasi sehingga berdampak pada meningkatnya kejadian penyakit akibat sanitasi buruk. Sumber air tanah (sumur) juga tercemar sehingga warga kehilangan sumber air bersih untuk kebutuhan dasar.

Tim kedua yang diterjunkan di Kota Bima memiliki tugas untuk menindaklanjuti kajian yang telah dilakukan oleh tim pertama. Oleh karena itu, tim memutuskan untuk menerapkan teknologi alat PAH di daerah yang terdampak banjir yang dilaksanakan oleh tim kedua.

Pemanenan air hujan adalah kegiatan 
menampung air hujan secara lokal dan menyimpannya melalui berbagai teknologi, untuk memenuhi kebutuhan konsumsi atau kegiatan manusia. Pengertian yang lainnya adalah pengumpulan, penyimpanan, dan pendistribusian air hujan dari atap untuk penggunaan di dalam dan di luar rumah maupun bisnis. ${ }^{4}$ Menurut peraturan Menteri Negara Lingkungan Hidup No. 12 tahun 2009 pasal 3, kolam pengumpul air hujan adalah kolam atau wadah yang dipergunakan untuk menampung air hujan yang jatuh di atap bangunan (rumah, gedung perkantoran, atau industri) yang disalurkan melalui talang. ${ }^{5}$

Sebuah sistem pemanenan air hujan terdiri dari tiga elemen dasar yaitu area koleksi, sistem alat angkut, dan fasilitas penyimpanan. Tempat penampungan yang dipakai kebanyakan adalah atap rumah atau bangunan. Luas efektif atap dan bahan yang digunakan dalam membangun atap mempengaruhi efisiensi pengumpulan dan kualitas air. Sistem pengangkutan biasanya terdiri dari talang atau pipa yang menyalurkan air hujan yang jatuh di atas atap ke tangki air atau tempat penyimpanan lain. Baik pipa drainase maupun permukaan atap harus terbuat dari bahan lembam seperti kayu, plastik, aluminium, atau fiberglass untuk menghindari buruknya kualitas air. Air disimpan dalam tangki penyimpanan atau tadah yang juga harus terbuat dari bahan lembam. Beton bertulang, fiberglass, atau stainless steel adalah bahan yang cocok sebagai tangki penyimpanan. Tangki penyimpanan dapat dibuat sebagai bagian dari bangunan atau mungkin dibangun sebagai unit terpisah yang letaknya agak jauh dari bangunan. ${ }^{6}$

Ada berbagai teknik penerapan pemanenan air hujan yang dapat dipilih sesuai dengan kondisi setempat. Alat PAH dapat dibangun atau diletakkan di atas permukaan tanah, di bawah permukaan tanah, atau di bawah bangunan, disesuaikan dengan ketersediaan lahan. ${ }^{7}$ Alat $\mathrm{PAH}$ yang diletakkan di atas permukaan tanah mempunyai berbagai keunggulan, antara lain mudah dalam mengambil/ memanfaatkan airnya (pengalirannya dapat dengan metode gravitasi) dan mudah perawatannya. Volume penampung air hujan yang digunakan dalam sistem PAH harus disesuaikan dengan luas atap serta curah hujan setempat.

Di beberapa tempat di Indonesia di mana sumber daya air tawarnya terbatas, misalnya di wilayah pesisir serta pulau-pulau kecil di daerah Kalimantan, penampungan atau pemanenan air hujan merupakan hal yang sudah biasa dilakukan untuk memenuhi kebutuhan air minum. Penampungan dilakukan mulai dari skala yang kecil (rumah tangga) sampai dengan volume yang besar. ${ }^{8}$

Air hujan yang dikumpulkan oleh alat $\mathrm{PAH}$ menunjukkan hasil cukup baik berdasarkan standar baku mutu air bersih yang diterbitkan oleh Permenkes No. 416/Menkes/Per/IX/1990 (Tabel 1). Secara fisik, air hujan yang dipanen sudah sesuai dengan persyaratan kualitas air bersih dan air minum. pH air hujan yang dipanen dengan alat $\mathrm{PAH}$ lebih rendah bila dibandingkan dengan standar baku air minum $(6,5-8,5)$, tetapi air tersebut masih tergolong air bersih karena telah memenuhi standar baku mutu air bersih dari air hujan $(\mathrm{pH}$ minimal 5,5). Hasil uji Coliform juga menunjukkan hasil yang jauh lebih rendah dibandingkan dengan kadar maksimum yang diperbolehkan oleh peraturan standar baku mutu air bersih. ${ }^{9}$ Meskipun demikian, alat $\mathrm{PAH}$ yang dipasang masih kurang untuk daerah dengan luas seperti Kota Bima. Akan jauh lebih besar manfaatnya apabila alat PAH dipasang di lebih banyak titik yang strategis seperti di masjid dan pos keamanan lingkungan (poskamling). Selain itu, sebagai upaya pencegahan, perlu dibentuk komunitas sekolah sungai untuk menjaga kebersihan sungai (contohnya membersihkan sungai 3 hari sekali) serta pemberian pendidikan kepada masyarakat di sekitar sungai dengan penyuluhan agar masyarakat tidak membuang sampah di sungai dan tidak mendirikan bangunan di bibir sungai.

\section{Kesimpulan}

Dari kegiatan yang dilaksanakan ditemukan ancaman wabah penyakit menular dan kualitas air yang buruk akibat banjir yang menyebabkan penumpukan sampah dan lumpur. Teknologi $\mathrm{PAH}$ yang diterapkan di Puskesmas Penanae 
dan Puskesmas Mpunda memberikan hasil yang telah memenuhi standar dan dapat membantu mengatasi permasalahan kualitas air yang buruk pada bencana banjir. Namun demikian, agar manfaat yang diperoleh lebih besar, alat PAH perlu dipasang di lebih banyak tempat yang strategis mengingat luasnya area terdampak banjir di Kota Bima.

\section{Ucapan terima kasih}

Ucapan terima kasih kami tujukan kepada Keluarga Alumni Universitas Gadjah Mada Fakultas Kedokteran (KAGAMADOK), Pemerintah Kota Bima, Dinas Kesehatan Kota Bima, Puskesmas Penanae, dan Puskesmas Mpunda.

\section{Daftar pustaka}

1. Yuniartanti RK. Rekomendasi adaptasi dan mitigasi bencana banjir di Kawasan Rawan Bencana (KRB) banjir Kota Bima. Journal of Regional and Rural Development Planning. 2018;2(2):118-32.

2. Badan Nasional Penanggulangan Bencana Republik Indonesia. Data dan informasi bencana Indonesia [Internet]. Jakarta: Badan Nasional Penanggulangan Bencana Republik Indonesia; 2016 [updated 2016 Jun]. Available from: https://bnpb.cloud/dibi/

3. Badan Nasional Penanggulangan Bencana Republik Indonesia. Indeks risiko bencana Indonesia tahun 2013. Jakarta: Badan Nasional Penanggulangan Bencana Republik Indonesia; 2014. Report No.: 1.

4. An KJ, Lam YF, Hao S, Morakinyo TE, Furumai H. Multi-purpose rainwater harvesting for water resource recovery and the cooling effect. Water Res. 2015;86:116-21.

5. Kementerian Lingkungan Hidup Republik Indonesia. Program Penilaian Peringkat Kinerja Perusahaan dalam Pengelolaan Lingkungan Hidup. Jakarta: Kementerian Lingkungan Hidup Republik Indonesia; 2016.

6. Bikram B, Rituparna P, Pankaj B, Deka PC, Begum AM, Sarmah AK, et al. Improvement of traditional rain water harvesting structures for multiple use of water through IFS module under Farmers' Participatory Action Research Programme. Int J Trop Agric. 2015;33(2 Pt I):607-9.

7. Sepehri M, Malekinezhad $H$, Ilderomi AR, Talebi A, Hosseini SZ. Studying the effect of rain water harvesting from roof surfaces on runoff and household consumption reduction. Sustain Cities Soc. 2018;43:317-24.

8. Bouma JA, Hegde SS, Lasage R. Assessing the returns to water harvesting: A meta-analysis. Agric Water Manag. 2016;163:100-9.

9. Kementerian Kesehatan Republik Indonesia. Permenkes No. 416/Menkes/Per/IX/1990. Jakarta: Kementerian Kesehatan Republik Indonesia; 1990 